\title{
The Association of Glycemic Markers with Plasma Adipocytokine Levels in Women with Gestational Diabetes
}

\author{
Nida Oztop ${ }^{1}$, Zeynep Kusku-Kiraz ${ }^{2}$, Elmire Dervisoglu ${ }^{3}$, Nevin Dinccag ${ }^{1}$ and Sema Genc ${ }^{3^{*}}$ \\ ${ }^{1}$ Department of Internal Medicine, Division of Endocrinology and Metabolism, Istanbul University, Capa, Istanbul, 34093, Turkey \\ ${ }^{2}$ Department of Biochemistry, Eskisehir Osmangazi University, Eskisehir, 26480, Turkey \\ ${ }^{3}$ Department of Biochemistry, Istanbul University, Capa, Istanbul, 34093, Turkey
}

*Corresponding author: Sema Genc, Faculty of Medicine, Department of Biochemistry, Istanbul University, Capa, Istanbul, 34093,Turkey, Tel: +90 5324215112; E-mail: nsgenc@hotmail.com

Received date: Jul 23, 2016; Accepted date: Sep 02, 2016; Published date: Sep 05, 2016

Copyright: (c) 2016 Oztop N, et al. This is an open-access article distributed under the terms of the Creative Commons Attribution License, which permits unrestricted use, distribution, and reproduction in any medium, provided the original author and source are credited.

\begin{abstract}
Introduction: Alterations in the synthesis of cytokines have been demonstrated in gestational diabetes (GDM), but the association of cytokines with short- and long-term glycemic markers has not been defined clearly. In this study, the variations in the plasma levels of visfatin, TNF- $\alpha, \mathrm{IL}-1 \beta, \mathrm{IL}-6$, and IL-10 were investigated and theirassociations with glycemic markers - HbA1C, fructosamine, 1,5-anhydro-D-glucitol (1,5-AG), and continuous glucose monitoring system (CGMS) parameters were evaluated.
\end{abstract}

Material and methods: 33 pregnant women with GDM, and 20 pregnant women without any maternal and fetal disorder were comprised in the study. Three of the 33 women diagnosed with GDM required insulin therapy were excluded from the study. The visfatin, TNF- $\alpha$, IL-1 $1 \beta$, IL- 6 and IL-10 and 1,5-AG were determined by ELISA. HbA1C\% and fructosamine were also evaluated. Continuous glucose monitoring system (CGMS) was applied to the women with GDM.

Results: Serum IL- 6 and IL- $1 \beta$ levels were significantly high in GDM compared to controls $(p=0.039$, and $p=0.04$, respectively). An increase in TNF- $\alpha$ level by approximately $33 \%$ did not reach significant level. No significant interactions between BMI and cytokines were found. Visfatin levels were correlated with 1,5 AG $(r=0.557, p=0.001)$ and TNF- $\alpha$ concentration was correlated with HbA1C $(r=0.341, p=0.050)$. IL-1 $\beta$ was associated with both MAD\% and average glucose which are indices of CGMS $(p=0.004$ and $p=0.008)$.

Conclusions: Increased IL-6, IL-1 $\beta$, and TNF- $\alpha$, and their correlation with short- or longterm glycemic markers present an evidence for the roles of these cytokines and visfatin on carbohydrate metabolism in the course of gestational process and gives a priority to proinflammatory cytokine profile in gestational diabetes.

Keywords: Gestational diabetes mellitus; Dipocytokines; 1,5anhydro-D-glucitol (1,5-AG); Continuous glucose monitoring system; HbAlc

\section{Introduction}

Gestational diabetes mellitus (GDM) is a result of carbohydrate intolerance which occurs during pregnancy. In one third of patients, it returns to normal glucose tolerance after delivery. Alterations in maternal metabolism occur during normal pregnancy in order to provide the needs for fetus and placenta and insulin secretion increases 2-2.5 fold to maintain the euglycemic state. A pregnancy accompanied by hyperinsulinemia represents a causative factor for insulin resistance and leads to vascular dysfunction via inflammatory mediators. Insulin sensitivity also is decreased progressively owing to the diabetogenic effects of gestational hormones and proinflammatory cytokines have been attributed to be causative factors of insulin resistance $[1,2]$.

Gestational diabetes associates with low grade inflammatory response and dysregulated synthesis or function of pro-inflammatory cytokines, i.e. interleukin (IL)-6, IL-1 $\beta$, IL-10, tumor necrosis factor (TNF)- $\alpha$, and visfatin. These compounds together with inflammatory cells such as macrophages participate the initiation and progression of insulin resistance, GDM and diabetes mellitus $[3,4]$. The infiltration of macrophages in pancreatic and adipose tissue causes enhanced production of proinflammatory cytokines while other immune cells can also contribute the infiltration [5]. This massive exposure of pancreatic $\beta$ - cells results in low insulin synthesis and apoptosis, thus causing high blood glucose levels [6,7].

High glucose level directly affects islet cells inducing pro-apoptotic receptor FAS on $\beta$-cells, leading to IL-1 $\beta$ activation as a final effector way [8]. Several cytokines-TNF- $\alpha$, IL-6- and some chemokines are found in plasma of the patients have been shown IL-1 dependent [9]. TNF, IL-1 $\beta$ and IL- 6 have been reported to promote insulin resistance and reflect the innate immune system activation [10]. TNF- $\alpha$ affects on glucose metabolism by either inhibiting insulin signaling or reducing the expression of regulatory molecules [11,12]. The roles of TNF- $a$ and IL- $1 \beta$ as well as IL- 6 have been emphasized in the pathogenesis of insulin resistance and gestational diabetes [13-15]. On the other hand, IL-10 is an anti-inflammatory cytokine specifically counteracting with the responses mediated by TNF- $\alpha[16,17]$. IL-10 works as a modulator of maternal immune response against fetal allograft, and its level increases during pregnancy [18]. Low concentrations of IL-10 in 
plasma have been found to associate with gestational diabetes $[15,19]$ Intensity of hyperglycemic situation has been shown to alter both TNF- $\alpha$ and IL-10 levels leading to higher TNF- $\alpha /$ IL-10 ratio [20]. An adipocyte-derived protein, visfatin is known to be mediated by glucose and insulin levels. Although plasma levels of visfatin have been found increased in cases with type 2 diabetes, metabolic syndrome and obesity [21-23], opposite findings have also been reported [24].

In women with GDM, variations in plasma cytokine levels have previously been demonstrated $[25,26]$. However, the association of cytokines with short- and long-term glycemic markers has not been defined clearly. HbA1C is a glycation product of hemoglobin defined as a long-term glycemic marker, representing the glycemic changes over 90 days. It is known that a considerable lag-time exists between actual glycemic changes and $\mathrm{HbAlC}$ response. Therefore, the improvement or deteriation of blood glucose level in short period are not reflected exactly with $\mathrm{HbA1C}$. However, fructosamine levels indicate all glycated proteins including albumin, lipoprotein and globulin and has been reported to show larger intra-individual variability compared with $\mathrm{HbA1C}$ [27]. Serum protein concentrations and dilutional anemia which may develop during pregnancy can affect fructosamine levels [28].

1,5-Anhydroglucitol (AG), a sensitive very short-term marker, reflects glycemic status during $24 \mathrm{~h}$ period and responses rapidly to changes in plasma glucose concentrations [29]. Serum 1,5-AG has been reported to exhibit postprandial hyperglycemia more accurately than HbA1C [30]. Therefore, the assessment of metabolic control in GDM patients is recommended to accomplish with measuring 1,5 AG together with $\mathrm{HbA1C}$ [31].

In the present study, the variations in the plasma levels of visfatin, TNF- $\alpha$, IL- $1 \beta$, IL- 6 , and IL-10 were investigated and their associations with glycemic markers -HbA1C, fructosamine, 1,5-anhydro-D-glucitol (1,5-AG)-, and continuous glucose monitoring system (CGMS) parameters were evaluated.

\section{Materials and Methods}

\section{Patients}

The study group consisted of 33 pregnant women diagnosed with gestational diabetes (median age 32, range 20-47) and pregnant women without any maternal and fetal disorder $(n=20$, median age 28 , range 18-37) served as controls. Median gestational age was 36 weeks.

All pregnant women attending to the Istanbul Faculty of Medicine, Department of Gynecology and Obstetrics are screened for GDM between 24th and 26th weeks by a two-step GDM screening test according to American Diabetes Association (ADA) [32]. The glycemic control of women diagnosed with GDM was provided only by diet and exercise. Three of the 33 women diagnosed with GDM required insulin therapy were excluded from the study together with the patients with renal failure, hepatic insufficiency, severe anemia. The treatment protocol was planned to maintain normoglycemic state throughout the pregnancy. Control subjects were compared with the women with GDM for maternal age, parity, gestational age at delivery, birth weight, and family history of DM. All women delivered a live birth.

Venous blood samples were collected in vacutainer serum separator tubes (Becton Dickinson, Plymouth, UK), centrifuged at $+4^{\circ} \mathrm{C}$ for 15 minutes, at $1000 \times \mathrm{g}$. Serum aliquots were stored at $-80^{\circ} \mathrm{C}$ for the measurements of TNF- $\alpha$, IL-10, IL-1 $\beta$, IL- 6 and 1,5-AG levels. Serum fructosamine, HbA1C levels were carried out on the same day. For $\mathrm{HbA1C}$ assay, blood samples were collected in vacutainer tubes containing K2-EDTA. Continuous glucose monitoring system (CGMS) was applied for $72 \mathrm{~h}$ to the women with GDM.

The study was approved by the Ethical Committee of Istanbul University (project \# 2014/399). An informed consent was taken from each patient.

\section{Methods}

HbA1C levels were determined using cation- exchange high performance liquid chromatography [HPLC] with Bio-Rad Turbo II (Bio-Rad, Richmond, California, USA) and fructosamine levels were measured with colorimetric method using Roche modular system (Roche, Mannheim, Germany) within four hours following blood drawn.

Serum visfatin, IL-6, TNF- $\alpha$, IL-10, IL-1 $\beta$ concentrations were determined by the enzyme-linked immunosorbent method (ELISA, Assaypro, St Charles, USA) with intra-assay coefficient of variation (CV) were below $5 \%$, and interassay $\mathrm{CV}<8 \%$. Serum visfatin level was measured using ELISA kit (Sunred Biological Technology, Shanghai, China) with intra- and inter-assay CVs being $9.0 \%$ and $11 \%$, respectively. 1,5 AG levels were measured with ELISA technique with intra-assay CV\% 2.5 and inter-assay CV 5.0\% (Cusabio, Wuhan, China). Reference values of $1,5-\mathrm{AG}$ was $14.4-30.2 \mathrm{mg} / \mathrm{L}$ in healthy subjects [33].

The results of CGMS were analyzed for $72 \mathrm{~h}$ period before blood collection for 1,5-AG and HbA1C measurement in 33 women. Mean glycemia and its standard deviation, mean maximum and minimum glucose levels and the percentage of mean absolute difference (MAD\%) were calculated using CGMS software using 12 measurements through 72 hours (Medtronic, Minneapolis, MN, USA).

Demographic values (weight, height and waist/hip circumferences) were measured and BMIs of subjects were calculated as the ratio between weight and height squared $\left(\mathrm{kg} / \mathrm{m}^{2}\right)$.

\section{Statistical analysis}

Data were analyzed using SPSS 15 (SPSS, Chicago, IL, USA). The results were expressed as mean $\pm \mathrm{SD}$ and median [range]. The normality of the data distribution was evaluated by the KolmogorovSmirnov test. Mann-Whitney U-test was performed to compare the data between the groups. Correlation analyses were carried out by the Pearson test. Interaction effect between BMI and cytokine levels was tested with a two-way ANOVA model. Statistical significance was defined as $\mathrm{p}<0.05$.

\section{Results}

Baseline demographic characteristics of the subjects are shown in Table 1 . There was no significant difference between the groups with respect to age, weeks of gestation, average weight gain during pregnancy, parity, or family history of type 2 diabetes. Only BMI of two groups were significantly different $(\mathrm{p}=0.006)$.

Data obtained from the women with GDM were compared with those in the control group (Table 2). Serum IL-6 and IL-1 $\beta$ levels were found significantly high in the former $(\mathrm{p}=0.039$, and $\mathrm{p}=0.04$, respectively). An increase in TNF- $\alpha$ level by approximately $33 \%$ was observed, but the difference did not give a statistical significance. 
Visfatin levels in GDM group showed a slight decrease, while IL-10 levels were similar in both groups. No significant interactions were found between maternal BMI and cytokines, therefore the analyses on IL-6 ( $\mathrm{p}=0.03)$ and IL-1 $\beta(\mathrm{p}=0.04)$ were not adjusted for BMI.

\begin{tabular}{|l|l|l|}
\hline Demographic characteristics & GDM [n=30] & Control group [n=20] \\
\hline Age [years] & $32[20-47]$ & $28[18-37]$ \\
\hline Parity & $3[1.0-6.0]$ & $1.0[1.0-3.0]$ \\
\hline BMI [kg/m²] & $26.4[17.3-44.1]$ & $24[21-26]$ \\
\hline Gestational weeks at delivery & $36[35-38]$ & $35[34-38]$ \\
\hline Birth weight [g] & $3190[2390-3800]$ & $3177[2150-3500]$ \\
\hline Family history of DM [n] & 20 & 8 \\
\hline
\end{tabular}

Table 1: Demographic characteristics and birth outcomes of the study groups. Median [range].

\begin{tabular}{|c|c|c|c|}
\hline & GDM & Control & $p$ \\
\hline Visfatin [ng/mL] & $3.8 \pm 2.9$ & $4.97 \pm 5.47$ & 0.426 \\
\hline IL-6 [pg/mL] & $3.1 \pm 0.9$ & $2.7 \pm 0.7$ & $0.04^{*}$ \\
\hline TNF- $\alpha[p g / m L]$ & $6.61 \pm 7.53$ & $4.41 \pm 3.03$ & 0.59 \\
\hline IL-1 $1 \beta[p g / m L]$ & $1.62 \pm 0.4$ & $1.39 \pm 0.2$ & $0.04^{*}$ \\
\hline IL-10 [pg/mL] & $88.3 \pm 66.5$ & $71.8 \pm 13.8$ & 0.73 \\
\hline TNF- $\alpha /$ IL-10 & $0.08 \pm 0.1$ & $0.06 \pm 0.05$ & 0.56 \\
\hline $1,5 \mathrm{AG}[\mathrm{mg} / \mathrm{L}]$ & $17.2 \pm 4.3$ & $20.0 \pm 5.8$ & 0.06 \\
\hline $\mathrm{HbA} 1 \mathrm{C} \%[\mathrm{mmol} / \mathrm{mol}]$ & $5.1 \pm 0.3[32 \pm 4]$ & $4.9 \pm 0.17[30 \pm 2]$ & 0.11 \\
\hline $\begin{array}{l}\text { Fructosamine } \\
{[\mu \mathrm{mol} / \mathrm{L}]}\end{array}$ & $2.1 \pm 0.3$ & - & - \\
\hline $\begin{array}{l}\text { Average glucose } \\
{[\mathrm{mg} / \mathrm{dL}]}\end{array}$ & $86.1 \pm 0.7$ & - & - \\
\hline Min. glucose [mg/dL] & $54.7 \pm 11.9$ & - & - \\
\hline Max. glucose [mg/dL] & $131.4 \pm 23.2$ & - & - \\
\hline MAD\% & $6.84 \pm 3.06$ & - & - \\
\hline
\end{tabular}

Table 2: Adipocytokine, glycemic markers, and CGMS indices in women with gestational diabetes [means $\pm \mathrm{SD}$ ].

Significant correlations between glycemic markers and cytokines were obtained in the GDM group. Visfatin levels were correlated with 1,5 AG ( $\mathrm{r}=0.557, \mathrm{p}=0.001)$ and TNF- $\alpha$ concentration was correlated with $\mathrm{HbAlC}(\mathrm{r}=0.341, \mathrm{p}=0.050)$. When the indices of CGMS were evaluated, mean glucose concentration was 85.1 (10.7) $\mathrm{mg} / \mathrm{dL}$, minimal glucose level was $54.7(11.9) \mathrm{mg} / \mathrm{dL}$, and maximum glucose level was 131.4 (23.3) $\mathrm{mg} / \mathrm{dL}$. IL-1 $\beta$ was significantly asso0ciated with both the percentage of MAD\% and average glucose level $(r=0.524$, $\mathrm{p}=0.004$ and $\mathrm{r}=0.488$ and $\mathrm{p}=0.008$, respectively). No significant association was found between fructosamine levels and any of the cytokines. Significant associations were also obtained between proinflammatory cytokines; visfatin levels were associated with IL-10 $[\mathrm{r}=0.565, \mathrm{p}=0.001]$, TNF- $\alpha$ was associated with IL-6 $(\mathrm{r}=-0.318$, $\mathrm{p}=0.032)$ and IL-10 $(\mathrm{r}=0.588, \mathrm{p}=0.000)$. IL- $1 \beta$ concentrations were correlated with TNF- $\alpha$ /IL-10 ratio $(\mathrm{r}=-0.350, \mathrm{p}=0.01)$.

\section{Discussion}

Pro- and anti-inflammatory cytokines secreted from placenta contribute to normal fetal growth and development and they also take part in maternal immunity. The balance between pro- and antiinflammatory cytokines shows variations during different gestational stages. The regulatory function of IL-10 in this delicate equilibrium has been emphasized in the course of normal pregnancy [18].

In the present study, plasma levels of adipocytokines (visfatin, IL-6, TNF- $\alpha$, IL- $1 \beta$ - and IL-10) were determined in GDM patients and the relation between cytokine levels and long- and short-term glycemic markers was evaluated. IL- 6 and IL- $1 \beta$ levels were found elevated in GDM patients. Although TNF- $\alpha$ levels showed 33\% increment, the difference between groups did not reach a significant level. During pregnancy, increased TNF- $\alpha$ and decreased IL-10 levels have been observed in the late term $[13,15,19]$. However, some researchers did not find any differences with respect to the stages of pregnancy [19]. Our findings were in agreement with the latter. In GDM patients, Moreli et al. have reported increased levels of TNF- $\alpha$ in placenta and maternal plasma, together with decreased IL-10 levels in plasma, and introduced the precedence of an altered cytokine profile in hyperglycemic pregnancies [20]. Despite the increase in placental TNF- $\alpha$, its plasma levels may not alter due to the presence of various factors which is known to affect the transition of placental secretion through the circulation. Among these factors, hypoxia resulted from hyperglycemic environment and pre-existing inflammatory condition should be taken into account $[34,35]$. Previous studies with regard to IL-10 levels in GDM are not concordant $[15,19,25,26,36]$. Our results are in good agreement with the researchers who reported no difference in maternal IL-10 levels during GDM [26,36,37].

When the association between glycemic markers and cytokines were investigated, IL-1 $\beta$ levels were associated with average glucose level and MAD\% which are indices of CGMS and reflect the fluctations of glucose levels in short-term. This association may be explained by the ongoing inflammatory condition which is triggered due to excess glucose. It has been shown that IL- $\beta$ system is induced by hyperglycemia [5]. Other cytokines and inflammatory mediators are accepted to be IL-1 dependent [9]. On the other hand, no association was obtained between 1,5 AG and IL- $1 \beta$. This short-term marker was correlated only with visfatin levels. 1,5 AG level has been reported to demonstrate negative correlation with high glucose levels in poorly controlled diabetes [38]. It has been shown that visfatin stimulates glucose uptake and inhibits glucose release from the hepatocytes by inducing the expression of peroxisome-proliferator-activated receptor$\gamma($ PPAR $-\gamma)$ which might be involved in developing insulin resistance [39]. Our findings support an auxiliary action of visfatin for glucose homeostasis in accordance with a previous study [40].

TNF- $\alpha$ levels were associated only with $\mathrm{HbA1C}$ which is long-term glycemic marker, while no association was obtained with 1,5 AG and $\mathrm{MAD} \%$. In a previous study, it has been reported that increases in plasma TNF- a levels associated with the glycated hemoglobin in GDM patients [41]. IL-6 has been shown to exert inflammatory properties and being secreted under hyperglycemic conditions [42]. Nevertheless, the roles of IL- 6 in insulin resistance is controversial. While IL-6 secreted from liver and adipocytes have been related with insulin resistance, IL-6 derived from skeletal muscle has opposite effect 
$[43,44]$. In our study, IL-6 levels were found increased. There are several studies reported high levels of IL-6 and decreased levels of IL-10 in GDM patients $[45,46]$, whereas some others did not confirm these results $[37,47]$. In our study, we could not find any association among IL-10 and IL-6 levels with any of the glycemic markers.

Our study has some limitations. First, the study population is limited. Second, our study was performed in GDM patients close to term. Measurements of cytokine levels together with glycemic markers at several terms of the gestational period would have given a better understanding about the impact of cytokines on carbohydrate metabolism.

The increased levels of proinflammatory cytokines, IL-6, IL-1 $\beta$, and TNF- $\alpha$, and their correlation with short- or long-term glycemic control markers present an evidence for the roles of these cytokines and visfatin on carbohydrate metabolism in the course of gestational process and gives a priority to proinflammatory cytokine profile among laboratory tests in GDM patients.

\section{Acknowledgements}

We would like to thank Prof. Dr. Figen Gurdol for her contribution to the manuscript.

\section{Conflict of Interest}

The authors declare that they have no conflict of interest.

\section{References}

1. Heitritter SM, Solomon CG, Mitchell GF, Skali-Ounis N, Seelvy EW (2005) Subclinical inflammation and vascular dysfunction in women with previous gestational diabetes. J Clin Endocrinol Metab 90: 3983-3988.

2. Winkler G, Cseh K, Baranyi E, Melczer Z, Speer G, et al. (2002) Tumor necrosis factor system in insulin resistance in gestational diabetes. Diabetes Res Clin Pract 56: 93-99.

3. Hotamisligil GS (2006) Inflammation and metabolic disorders. Nature 444: 860-867.

4. Shaul ME, Bennett G, Strissel KJ, Greenberg AS, Obin MS (2010) Dynamic, M2-like remodeling phenotypes of CD11c+ adipose tissue macrophages during high fat diet induced obesity in mice. Diabetes 59: 1171-1181.

5. Calderon B, Suri A, Pan XO, Mills JC, Unanue ER (2008) IFN-gammadependent regulatory circuits in immune inflammation highlighted in diabetes. J Immunol 181: 6964-6974.

6. Meier JJ, Ritzel RA, Maedler K, Gurlo T, Butler PC (2006) Increased vulnerability of newly forming beta cells to cytokine-induced cell death. Diabetologia 49: 83-89.

7. Welsh N, Cnop M, Kharroubi I, Bugliani M, Lupi R, et al. (2005) Is there a role for locally produced interleukin-1 in the deleterious effects of high glucose or the type 2 diabetes milieu to human pancreatic islets? Diabetes 54: 3238-3244.

8. Böni-Schnetzler M, Thorne J, Parnaud G, Marselli L, Ehses JA, et al. (2008) Increased interleukin (IL)-1beta messenger ribonucleic acid expression in beta -cells of individuals with type 2 diabetes and regulation of IL-1beta in human islets by glucose and autostimulation. J Clin Endocrinol Metab 93: 4065-4074.

9. Donath MY, Størling J, Maedler K, Mandrup-Poulsen T (2003) Inflammatory mediators and islet beta-cell failure: a link between type 1 and type 2 diabetes. J Mol Med (Berl) 81: 455-470.

10. Donath MY, Shoelson SE (2011) Type 2 diabetes as an inflammatory disease. Nat Rev Immunol 11: 98-107.
11. Rui L, Aguirre V, Kim JK, Shulman GI, Lee A, et al. (2001) Insulin/IGF-1 and TNF-alpha stimulate phosphorylation of IRS-1 at inhibitory Ser307 via distinct pathways. J Clin Invest 107: 181-189.

12. Moller DE (2000) Potential role of TNF-alpha in the pathogenesis of insulin resistance and type 2 diabetes. Trends Endocrinol Metab 11: 212-217.

13. Kirwan JP, Hauguel-De Mouzon S, Lepercq J, Challier JC, Huston-Presley L, et al. (2002) TNF-alpha is a predictor of insulin resistance in human pregnancy. Diabetes 51: 2207-2213.

14. Coughlan MT, Oliva K, Georgiou HM, Permezel JMH, Rice GE (2001) Glucose -induced release of tumoutr necrosis factor-alpha from human placental and adipose tissues in gestational diabetes mellitus. Diabetic Medicine 18: 921-927.

15. Atègbo JM, Grissa O, Yessoufou A, Hichami A, Dramane KL, et al. (2006) Modulation of adipokines and cytokines in gestational diabetes and macrosomia. J Clin Endocrinol Metab 91: 4137-4143.

16. Agarwal R, Loganath A, Roy AC, Wong YC, Ng SC (2000) Effect of Thelper 1 cytokines on secretion of T-helper 2 cytokines by term trophoblast cells in culture. Gynecol Endocrinol 14: 305-310.

17. Moreli JB, Ruocco AMC, Vernini JM, Rudge MV, Calderon IM (2012) Interleukin 10 and tumor necrosis factor-alpha in pregnancy: aspects of interest in clinical obstetrics. ISRN Obstet Gynecol 2012: 230742.

18. Thaxton JE, Sharma S (2010) Interleukin-10: a multi-faceted agent of pregnancy. Am J Reprod Immunol 63: 482-491.

19. Kuzmicki M, Telejko B, Zonenberg A, Szamatowicz J, Kretowski A, et al. (2008) Circulating pro- and anti-inflammatory cytokines in Polish women with gestational diabetes. Horm Metab Res 40: 556-560.

20. Moreli JB, Corrêa-Silva S, Damasceno DC, Sinzato YK, Lorenzon-Ojea AR, et al. (2015) Changes in the TNF-alpha/IL-10 ratio in hyperglycemiaassociated pregnancies. Diabetes Res Clin Pract 107: 362-369.

21. Sadri-Rossa P, Oliveira CSV, Giuffrida FMA, Reis AF (2010) Visfatin, glucose metabolism and vascular disease: a review of evidence. Diabetology \& Metabolic Syndrome 2: 21.

22. Filippatos TD, Derdemezis CS, Gazi IF, Lagos K, Kiortsis DN, et al. (2008) Increased plasma visfatin levels in subjects with the metabolic syndrome. Eur J Clin Invest 38: 71-72.

23. Lewondowski KC, Stojanovic N, Press M, Tuck SM, Szosland K, et al (2007) Elevated serum levels of visfatin in gestational diabetes: a comparative study across various degree of glucose tolerance. Diabetologia 50: 1033-1037.

24. Chan TF, Chen YL, Lee CH, Chou FH, Wu LC, et al. (2006) Decreased plasma visfatin concentrations in women with gestational diabetes mellitus. J Soc Gynecol Investig 13: 364-367.

25. Montazeri S, Nalliah S, Radhakrishnan AK (2010) Is there a genetic variation association in the IL-10 and TNF alpha promoter gene with gestational diabetes mellitus. Hereditas 147: 94-102.

26. Gueuvoghlanian-Silva BY, Torloni MR, Mattar R, de Oliveira LS, Scomparini FB, et al. (2012) Profile of inflammatory mediators in gestational diabetes mellitus: phenotype and genotype. Am J Reprod Immunol 67: 241-250.

27. Howey JE, Bennet WM, Browning MC, Jung RT, Fraser CG (1989) Clinical utility of assays of glycosylated haemoglobin and serum fructosamine compared: use of data on biological variation. Diabet Med 6: 793-796.

28. Hashimoto K, Koga M (2015) Indicators of glycemic control in patients with gestational diabetes mellitus and pregnant women with diabetes mellitus. World J Diabetes 6: 1045-1056.

29. Dungan KM (2008) 1,5-anhydroglucitol (GlycoMark) as a marker of short-term glycemic control and glycemic excursions. Expert Rev Mol Diagn 8: 9-19.

30. Dungan KM, Buse JB, Largay J, Kelly MM, Button EA, et al. (2006) 1,5anhydroglucitol and postprandial hyperglycemia as measured by continuous glucose monitoring system in moderately controlled patients with diabetes. Diabetes Care 29: 1214-1219. 
Citation: Oztop N, Kusku-Kiraz Z, Dervisoglu E, Dinccag N, Genc S (2016) The Association of Glycemic Markers with Plasma Adipocytokine Levels in Women with Gestational Diabetes. J Diabetes Metab 7: 699. doi:10.4172/2155-6156.1000699

Page 5 of 5

31. Dworacka $M$, Wender-Ozegowska E, Winiarska $H$, Borowska $M$, Zawiejska A, et al. (2006) Plasma anhydro-D-glucitol (1,5-AG) as an indicator of hyperglycaemic excursions in pregnant women with diabetes. Diabet Med 23: 171-175.

32. American Diabetes Association (2014) Standards of medical care in diabetes Diabetes Care 37: S19.

33. Dworacka M, Winiarska H, Szymanska M, Kuczynski S, Szczawinska K, et al. (2002) 1,5-anhydro-D-glucitol: a novel marker of glucose excursions. Int J Clin Pract Suppl 2: 40-44.

34. Calderon IM, Damasceno DC, Amorin RL, Costa RA, Brasil MA, et al (2007) Morphometric study of placental villi and vessels in women with mild hyperglycemia or gestational or overt diabetes. Diabetes Res Clin Pract 78: 65-71.

35. Moreli JB, Morceli G, De Luca AK, Magalhães CG, Costa RA, et al. (2012) Influence of maternal hyperglycemia on IL-10 and TNF-Ît production: the relationship with perinatal outcomes. J Clin Immunol 32: 604-610.

36. Georgiou HM, Lappas M, Georgiou GM, Marita A, Bryant VJ, et al (2008) Screening for biomarkers predictive of gestational diabetes mellitus. Acta Diabetol 45: 157-165.

37. Montazeri S, Nalliah S, Radhakrishnan AK (2010) Association between polymorphisms in human tumor necrosis factor-alpha [-308] and beta [252] genes and development of gestational diabetes mellitus. Diabetes Res Clin Pract 88: 139-145.

38. Akanuma Y, Morita M, Fukuzawa N, Yamanouchi T, Akanuma H (1988) Urinary excretion of 1,5-anhydro-D-glucitol accompanying glucose excretion in diabetic patients. Diabetologia 31: 831-835.

39. Fukuhara A, Matsuda M, Nishizawa M, Segawa K, Tanaka M, et al. (2001) Visfatin: a protein secreted by visceral fat that mimics the effects of insulin. Retracted Article Retraction notice 307: 426-430.
40. Pfützner A, Forst T (2006) Comment on: Haider DG, Schaller G, Kapiotis S, Maier C, Luger A, Wolzt M (2006) the release of the adipocytokine visfatin is regulated by glucose and insulin. Diabetologia 49:1909-1914. Diabetologia 49: 2795.

41. Gao XL, Yang HX, Zhao Y (2008) Variations of tumor necrosis factoralpha, leptin and adiponectin in mid-trimester of gestational diabetes mellitus. Chin Med J (Engl) 121: 701-705.

42. Devaraj S, Venugopal SK, Singh U, Jialal I (2005) Hyperglycemia induces monocytic release of interleukin- 6 via induction of protein kinase c\{alpha\} and -\{beta\}. Diabetes 54: 85-91.

43. Mooney RA (2007) Counterpoint:interleukin- 6 does not have a beneficial role in insulin sensitivity and glucose homeostasis. J Appl Physiol 102: 816-818.

44. Pedersen BK, Febbraio MA (2007) Point: Interleukin-6 does have a beneficial role in insulin sensitivity and glucose homeostasis. J Appl Physiol 102: 814-816.

45. Matarese G, Procaccini C, De Rosa V (2012) At the crossroad of T cells, adipose tissue, and diabetes. Immunol Rev 249: 116-134.

46. Fuentes L, Roszer T, Ricote M (2010) Inflammatory mediators and insulin resistance in obesity: role of nuclear receptor signaling in macrophages. Mediators Inflamm 2010: 219583.

47. Conti P, Kempuraj D, Kandere K, Di Gioacchino M, Barbacane RC, et al. (2003) IL-10, an inflammatory/inhibitory cytokine, but not always. Immunol Lett 86: 123-129. 